Article

\title{
The Effects of Commodity Discoveries on Small Open Economies: Empirical Evidence from the Falkland Islands
}

\author{
Bruce Morley \\ Department of Economics, University of Bath, Bath B2A 7AY, UK; bm232@bath.ac.uk
}

Received: 19 June 2019; Accepted: 18 October 2019; Published: 23 October 2019

\begin{abstract}
The aim of this study is to determine the effects of discovering oil on the performance of a small open economy, in this case the Falkland Islands. Using an event study approach and the return on one of the Falkland Islands' main companies, the results suggest that the discovery of oil has mostly had a positive effect on this company, which serves as a proxy for the Falkland Islands economy. In addition, using an EGARCH approach, there is evidence that the discovery of oil has reduced the volatility or risk of the company and therefore potentially the economy as a whole. However, when the oil price is added to the model, this tends to dominate the effect of the discovery.
\end{abstract}

Keywords: oil discovery; stock price; risk; event study; Q32; Q42

\section{Introduction}

The aim of this study is to determine the effects on the wider economy of a commodity discovery in a relatively small country in terms of the economy, such as the Falkland Islands, Greenland, or countries in the Caribbean such as Barbados. The discovery of commodities in all countries can have a substantial impact on the economy, which are usually beneficial, although there is also the potential for the much discussed 'resource curse'. This study concentrates on the discovery of oil, with regard to the recent discovery in the Falkland Islands. Using an event study type of analysis, the share price of the Falkland Islands Holdings (FIH) company, which is the main trading company in the Falkland Islands, is incorporated into the study with the event being the main discovery of oil in 2010. In addition, we use an EGARCH $(1,1)$ model to determine if the event has affected the volatility or risk as well as the return of FIH. There have been a number of studies that have assessed the effects of oil price shocks on asset prices in an event study context, such as Mensi et al. (2014), but this is the first as far as we know to assess the effects of oil discovery. The Falkland Islands was chosen due to the unique nature of the FIH company as the main trading company, so its share price should reflect the future prospects for the wider economy of the Falkland Islands.

There are many examples of commodity rich economies which have managed to benefit from the commodity discovery and production. A prime example is Norway, which has one of the highest per capita income levels in the world. However, other small economies have been less successful following the discovery of oil. Currently the most notorious example of this is Venezuela. The failure to benefit from being rich in resources is often referred to as the 'resource curse' and can be due to the 'Dutch Disease' (Sachs and Warner 1995) which refers to the appreciation of the exchange rate making the economy uncompetitive and exports subsequently fall. Other explanations are that the resource sector attracts the best workers and resources in an economy, so starving other sectors of these skills, and the volatility in the price of the commodity increases the uncertainty in the economic 
performance, so potentially reducing investment and growth. ${ }^{1}$ Torvik (2002) suggests the related area of rent-seeking as a potential cause, where the discovery of natural resources facilitates a transfer of resources from entrepreneurs in productive firms to rent-seeking firms. In addition, Torvik (2009) identifies the variation across resource abundant countries in terms of their prosperity, with some countries such as Norway and Botswana benefiting from the discovery whereas others such as Nigeria and Venezuela having a more negative effect. Torvik suggests these differences could be due to both economic and political factors along with institutional factors, with the savings rate being a good predictor of those likely to benefit from the discovery.

There have been a number of studies that have analysed the effects of discovering oil or similar commodities in medium sized economies, such as Listhaug (2005) on Norway, but few on the effects on the smaller economies, that tend to be dependencies of larger economies, such as the Falkland Islands and the UK. There is only a limited literature on the use of event studies to determine the effects of finding oil, which is the main contribution of this study. This is mainly due to a lack of data for smaller economies, especially measuring output or income. However, the share price of the Falkland Islands' main trading company could potentially provide useful information on how the discovery of oil could impact the wider economy, as share prices tend to reflect future economic performance.

Some of the literature has tried to analyse what factors determine if an economy benefits from the discovery of a commodity. For instance, Karl (1997), suggests one of the main factors that determine if it is a success, is the capacity of government and the country's institutions to handle the pressures and potential problems of the economic volatility caused by the commodity boom. Norway is suggested as an example of how a country can handle this sudden change in its circumstances well, although Listhaug (2005) questions some of the main policies used by Norway. Its main policy has been to set up a sovereign fund arguing that this enables future generations to benefit from the sudden increase in wealth and also potentially reduce excessive rent-seeking activities. In addition, it has invested long-term in its infrastructure, such as the production of renewable energy.

Following the introduction, we discuss the literature, methodology and the event dates. In the next section we analyse the data and the results, then discuss the conclusions and policy implications.

\section{Literature Review}

In the general literature relating to oil prices and stock returns, the most common finding is that oil prices have a negatively significant effect on stock price returns (Sadorsky 1999). However, there have only been a limited number of similar studies using the event study methodology to determine whether oil and commodity prices affect stock prices and the wider economy, although many studies on how events such as the Organisation of Petroleum Exporting Countries (OPEC) announcements effect oil prices e.g., (Loutia et al. 2016). One similar study is Romero-Meza et al. (2007), who have used Chilean stock prices and an event type of study to determine if nonlinearities have been affected by specific events. Given that Chile is a large exporter of commodities, they show that changes in commodity prices affect significantly Chilean stock prices, for instance on the 19 April, 1999 commodities reached their lowest prices in over 100 years and also on the 27 October, 1993 the price of copper suffered its largest decrease in 6 years. Zhang and Chen (2011) have also used an E-GARCH based approach to modelling how oil price shocks affect the Chinese stock prices. They found that jumps in Chinese stock prices were related to the expected movements in the world price of oil. They suggest this is unusual as in other studies using US data it is unexpected jumps in oil prices that affect the stock price.

A further approach to modelling how oil prices interact with stock prices and related to this study, has involved using various Generalised Autoregressive Conditional Heteroskedastistic (GARCH) based model to determine how oil price volatility directly affects stock prices, although not specifically

1 Overall the literature finds evidence of the resource curse occurring overall, although as Rosser (2006) suggests these studies should be treated with caution, due to measurement differences. 
using the event study approach. For instance, Elyasiani et al. (2011) have used a GARCH(1,1) approach to modelling the relationship between oil price volatility and the return on US industrial stock prices along with the volatility of these stock prices. They found that the oil price volatility has a significant effect on asset price risk across industries. Some studies have analysed the effects of oil prices on oil related stock prices, such as Broadstock et al. (2012). Again, they have used a GARCH based approach, but this study uses the multivariate Baba Engle Kraft and Kroner (BEKK) GARCH approach, estimating the conditional correlations between oil prices and returns on an energy-based stock market index in China. The results indicate a link between oil price changes and energy related stocks, especially after the 2007/08 financial crisis is incorporated into the model.

A further area of the event study literature related to this analysis, is the testing of how economic policy announcements have affected commodity prices. For instance, a number of studies have sought to determine whether specific monetary policy surprises have affected commodity prices. Rigobon and Sack (2004) initially modified the event study approach to determine the effects of monetary policies on stock prices. This approach has then been used by Scrimgeour (2014) to determine how monetary policies can affect commodity prices. This study finds that the surprises to monetary policy, such as through a sudden move in interest rates have a significant effect on commodity prices. They find that metal prices tend to be more sensitive than agricultural commodity prices to interest rate movements, although oil markets tend to move with the other main commodity markets.

\section{Materials and Methods}

The main hypothesis being tested here is that the discovery of oil has had a short-term effect on the FIH stock price in terms of both the return and volatility. A secondary hypothesis is that oil prices have a positive and significant effect on the FIH stock price return, especially since the discovery of oil reserves. The approach used to assess these hypotheses is an event study as discussed in Binder (1998), which assesses the impact of the discovery on the FIH stock price return and volatility. A lack of macroeconomic time series data means a direct analysis is problematic, however for this country there is a long time series of data available. This approach in using individual company stock returns in an event study has been used extensively in the literature, such as Castillo and Falzon (2018), who assess the impact of cyberattacks on the stock returns of cybersecurity firms. In that study, the market model is also used, but in that case to determine the excess return, which then uses a t-statistic to determine if the event had a significant effect. The approach used in this study is to determine the effect on the share price return based on the standard market model as in (1) with the addition of a dummy variable which takes the value of 1 for the event and 0 otherwise. The effect of the discovery is also measured with regard to the volatility or risk of the share price, by including a dummy variable in the conditional variance equation. This approach has been used before with the Generalised Autoregressive Conditional Heteroskedastistic (GARCH) type models, for instance Mensi et al. (2014) has used the Fractionally Integrated version or FIGARCH model, to determine the effects of OPEC announcements on oil prices and volatilities.

In this study the standard EGARCH(1,1)-M model of Nelson (1991) is used to determine the effects on the volatility. This approach has a number of advantages over other similar models such as the GARCH $(1,1)$ model, as it includes an asymmetric effect and also removes any potential problems relating to the non-negativity constraint. This specification incorporates an impulse dummy variable in both the mean and variance equations to account for the discovery. The basic model is the following:

$$
\begin{gathered}
\Delta l n s_{t}=\alpha_{0}+\alpha_{1} \Delta l n m_{t}+\alpha_{2} D_{t}+u_{t} \\
\ln \left(\sigma_{t}^{2}\right)=\lambda+\phi \ln \left(\sigma_{t-1}^{2}\right)+\gamma \frac{u_{t-1}}{\sqrt{\sigma_{t-1}^{2}}}+\beta\left[\frac{\left|u_{t-1}\right|}{\sqrt{\sigma_{t-1}^{2}}}-\sqrt{\frac{2}{\pi}}\right]+v D_{t}
\end{gathered}
$$


where $s_{t}$ is the stock price of FIH, $m_{t}$ is the main market index in the London stock exchange (FTSE All share index), and $D_{t}$ is a dummy variable representing the discovery of oil, $u_{t}$ is an error term, and $\sigma_{t}^{2}$ is the conditional variance of the error term. All stock market data and oil prices are logged and differenced, so transformed to a return format. If a gearing effect applies then the coefficient on the asymmetric term $(\gamma)$ should be negative, such that a negative shock increases volatility, as the level of borrowing relative to the property value will rise, increasing the riskiness of the property. The parameter $\phi$ captures simple persistence in volatility and $\beta$ measures the ARCH type of effect. If the dummy variable in the mean equation $\left(\alpha_{2}\right)$ is positive it indicates that following the discovery of oil it has positively affected the shares and the future economy. If the dummy variable in the variance equation $(v)$ is positive it suggests that the discovery of oil increased the volatility or risk of the shares and the wider economy.

A secondary set of tests were then carried out using the market model from (1) along with the addition of oil prices, to control for the effects of changes in oil prices on the potential revenue from the exploitation of the oil reserves, so the model would be:

$$
\Delta l n s_{t}=\alpha_{3}+\alpha_{4} \Delta \operatorname{lnm} m_{t}+\alpha_{5} D 1_{t}+\alpha_{6} \Delta \operatorname{lnoil}_{t}+v_{t}
$$

where oil $_{t}$ is the price of Brent crude oil. Additionally, the EGARCH(1,1) specification from Equation (2) has been used with this model too, with the addition of the oil variable as an extra determinant of the conditional volatility.

\section{FIH and the Event}

The economy of the Falkland Islands has traditionally been based on a single commodity which was wool (Shackleton 1983), although there have been suspicions that natural resources were present around the Islands for a considerable length of time. ${ }^{2}$ Over recent years the economy has become more diversified with a rise in the importance of fishing and tourism among other industries. Although there has been some evidence of oil reserves around the Falkland Islands since the early 1970s, it was not until after 2000 that the initial exploration began, with the main oil field Sea Lion being discovered in 2010.

The reason the Falkland Islands has been chosen is due to the data availability of stock prices for FIH, allowing an event type of study to be conducted. Much of the economy of the Falkland Islands is through FIH, which owns retails outlets, property, and infrastructure firms, such that a future expected change in the economy of the Falkland Islands would be reflected in the profitability of FIH and consequently its share price. However as with most event studies with stock prices, there are potential problems using FIH. Since 1998, when it was listed on the Alternative Investments Market in London (AIM), it has acquired two companies, a ferry company in the UK, and Monmart, which is a fine art distributor. At the same time, it has sold much of its interests in the oil exploration around the Falkland Islands. However, despite the majority of its business being in the UK and elsewhere, these are both relatively stable industries, so that much of the movement in the FIH share price will have been due to the speculation about the possibility of future oil based wealth and the positive effect this would have on the wider Falkland Islands economy.

The main discovery of oil was in the Sea Lion oil field, with the spud date being 15 April, 2010, which was when the drilling began, although the official announcement of the discovery was not until December of 2010. It is estimated that this field could produce anything up to 60,000 barrels a day. In this study, the April drilling is used as the main event, as there would have been an anticipation of finding oil based on the scientific surveys earlier and some appreciation of the find at this point

2 Although the discovery of oil will have ensured the Falklands economy is more diversified, there is some evidence of links in the volatility between oil and agricultural commodity markets reducing the effectiveness of the diversification (Fernandez-Diaz and Morley 2019). 
rather than the later official announcement. In this case, we have used a window of the previous and following month along with April. ${ }^{3}$ In a separate set of tests, an intercept dummy variable was used instead of the earlier impulse dummy. This was used to determine if the discovery has had a longer-term effect on the return and volatility of FIH and therefore the wider economy, taking the value of zero up until April 2010 and then one afterwards. This would also account for the fact that Sea Lion was the first and main discovery, although there have been a number of other smaller discoveries since then around the Falkland Islands.

\section{Data and Results}

The data is from January 1998 to April 2019, consisting of monthly data for the Falkland Island company share price, the FTSE All share index, and Brent crude oil prices. The stock price data has been taken from Yahoo Finance, the oil prices from FRED. The data starts in 1998 as this is the first available data and is monthly due to the lack of variation in the daily data. Table 1 contains the summary statistics, it is apparent that the FIH share price is the most volatile, whilst the FTSE all share index is the most stable. Based on the Augmented Dickey-Fuller (ADF) test for stationarity, with the modified Akaike criteria determining the lag length, all series are stationary in their return form. Plots of the data in return format are contained in Figures 1-3.

Table 1. Summary Statistics.

\begin{tabular}{cccccc}
\hline Variable & mean & max & min & sd & ADF \\
\hline Infih & 0.003 & 0.545 & -0.330 & 0.119 & $-15.497^{* * *}$ \\
$\Delta$ lnftse & 0.002 & 0.091 & -0.144 & 0.040 & $-5.069^{* * *}$ \\
Alnoil & 0.006 & 0.201 & -0.311 & 0.092 & $-8.314^{* * *}$ \\
\hline
\end{tabular}

Notes: The variables are logged and differenced. ${ }^{* * *}$ indicates significance at the $1 \%$ level of significance. Lag length based on modified Akaike criteria for Augmented Dickey-Fuller (ADF) test.

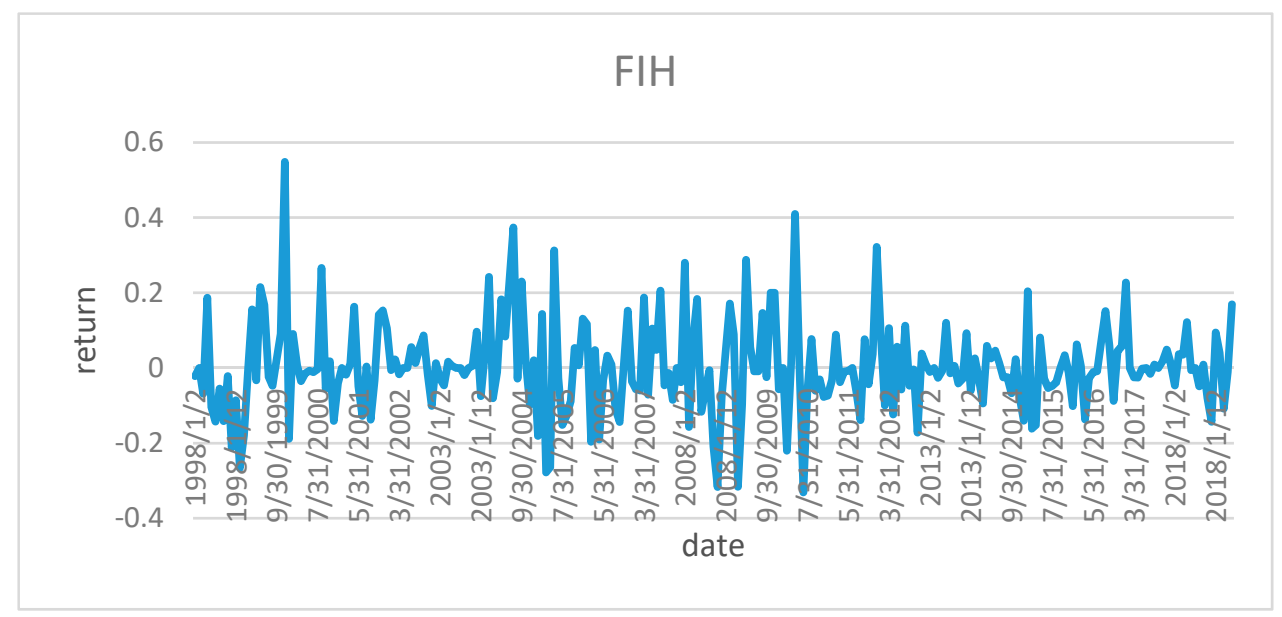

Figure 1. Falkland Islands Holdings (FIH) returns.

3 The results for this window have been reported, although other wider windows were also estimated, such as \pm 3 months, the results were not so significant so not reported. Also trying other dates, such as the official announcement date were not significant. Results available on request. 


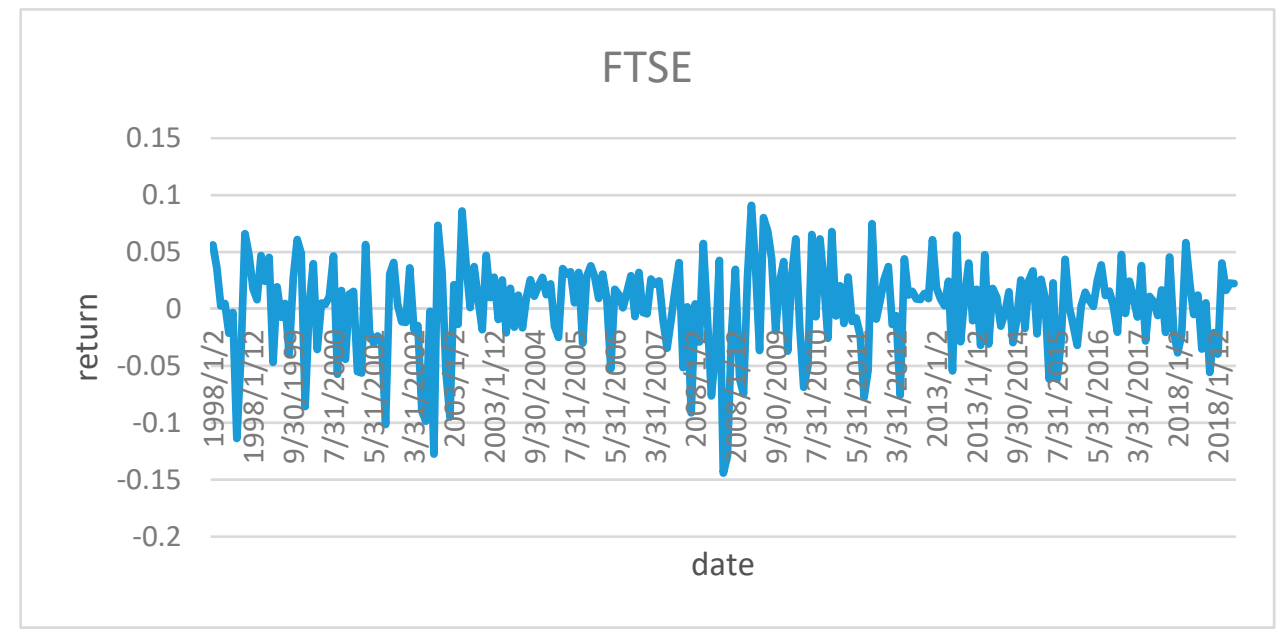

Figure 2. FTSE returns.

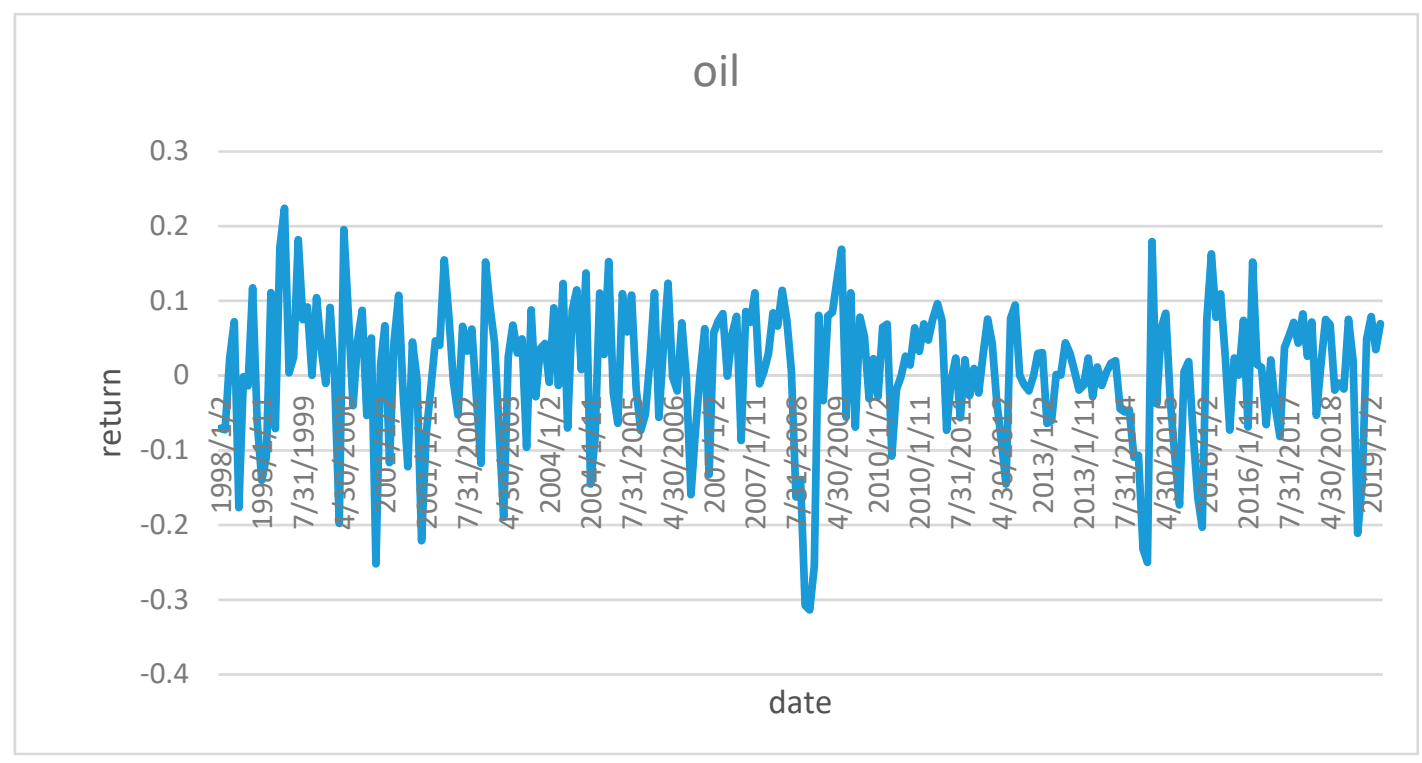

Figure 3. Oil returns.

In Table 2, the results indicate that in the mean equation the return on the market is significantly related to the return on $\mathrm{FIH}$, but only at the $10 \%$ level of significance. It suggests a $1 \%$ rise in the market produces a $0.334 \%$ rise in $\mathrm{FIH}$, suggesting that FIH is less volatile than the market. When only the dummy is included in the mean, it is positive and significant indicating that the discovery of oil has had a beneficial effect on the return to FIH in excess of the market return. However, for the intercept dummy, it is only significant when the dummy is in the mean equation alone; when added to the variance equation too, the dummy variables in the mean equation becomes insignificant. Testing for autocorrelation and residual $A R C H$ effect using the $Q(12)$ and $Q^{2}(12)$ statistics indicates neither are present.

The conditional volatility equation indicates no evidence of asymmetric adjustment and high persistence in the volatility, with over $94 \%$ of the volatility remaining one month later. Adding the dummy variable into the conditional volatility as well as the mean equation makes little difference as the event has had little effect on the volatility, although the event effect in the mean equation is now only significant at the $10 \%$ level. Adding the intercept dummy variable gives similar results, although when the dummy variable is also added to the conditional volatility equation, it has a significantly negative effect, suggesting a fall in volatility or risk since the finding of oil. The plot of the conditional volatility series is contained in Figure 4. It is clear that the volatility falls after 2010, so that by 2010 
the series has become relatively stable. This is due to a number of factors, partially because the price of oil was high and volatile during and just after the 2007-2008 financial crisis and also because the discovery of oil has meant the Falkland Islands economy is more stable, which is reflected in the FIH stock returns after 2010. It could also reflect the diversification of FIH with the purchases of the additional companies.

Table 2. Estimation of main Event study with EGARCH model.

\begin{tabular}{ccccc}
\hline Variable & $\mathbf{2 0 1 0 ( 3 - 5 )}$ & $\mathbf{2 0 1 0}(\mathbf{3}-\mathbf{5})$ & $\mathbf{2 0 1 0 - 2 0 1 9}$ & $\mathbf{2 0 1 0 - 2 0 1 9}$ \\
\hline$\alpha_{0}$ & 0.005 & 0.005 & $0.019^{* * *}$ & 0.008 \\
& $(0.699)$ & $(0.701)$ & $(2.399)$ & $(0.702)$ \\
$\alpha_{1}$ & $0.334^{*}$ & $0.334^{*}$ & $0.363^{* *}$ & $0.385^{* *}$ \\
& $(1.927)$ & $(1.913)$ & $(2.113)$ & $(2.323)$ \\
$\alpha_{2}$ & $0.174^{* *}$ & $0.166^{*}$ & $-0.024^{* *}$ & -0.01 \\
& $(2.616)$ & $(1.935)$ & $(2.496)$ & $(0.729)$ \\
$\lambda$ & $0.411^{* * *}$ & $0.430^{* * *}$ & $0.341^{* * *}$ & $7.772^{* * *}$ \\
$\beta$ & $(3.534)$ & $(3.57)$ & $(3.761)$ & $(34.472)$ \\
$\gamma$ & $0.235^{* * *}$ & $0.234^{* * *}$ & $0.229^{* * * *}$ & -0.049 \\
$\gamma$ & $(3.695)$ & $(3.591)$ & $(4.127)$ & $(1.287)$ \\
$\phi$ & -0.012 & -0.01 & -0.06 & 0.001 \\
& $(0.269)$ & $(0.226)$ & $(1.211)$ & $(0.01)$ \\
$v$ & $0.945^{* * *}$ & $0.941^{* * *}$ & $0.961^{* * *}$ & $0.956^{* * *}$ \\
$\mathrm{Q}(12)$ & $(39.723)$ & $(37.667)$ & $(53.295)$ & $(50.593)$ \\
$\mathrm{Q}^{2}(12)$ & & 0.104 & & $2.0944^{* * *}$ \\
\hline
\end{tabular}

Notes: See Equations (1) and (2) for model details. T-statistics in parentheses, $\mathrm{A}^{*}, * *, * * *$ indicates significance at the $10 \%, 5 \%$, and $1 \%$ levels. $\mathrm{Q}(12)$ and $\mathrm{Q}^{2}(12)$ test for autocorrelation and residual $\mathrm{ARCH}$ of order 12 .

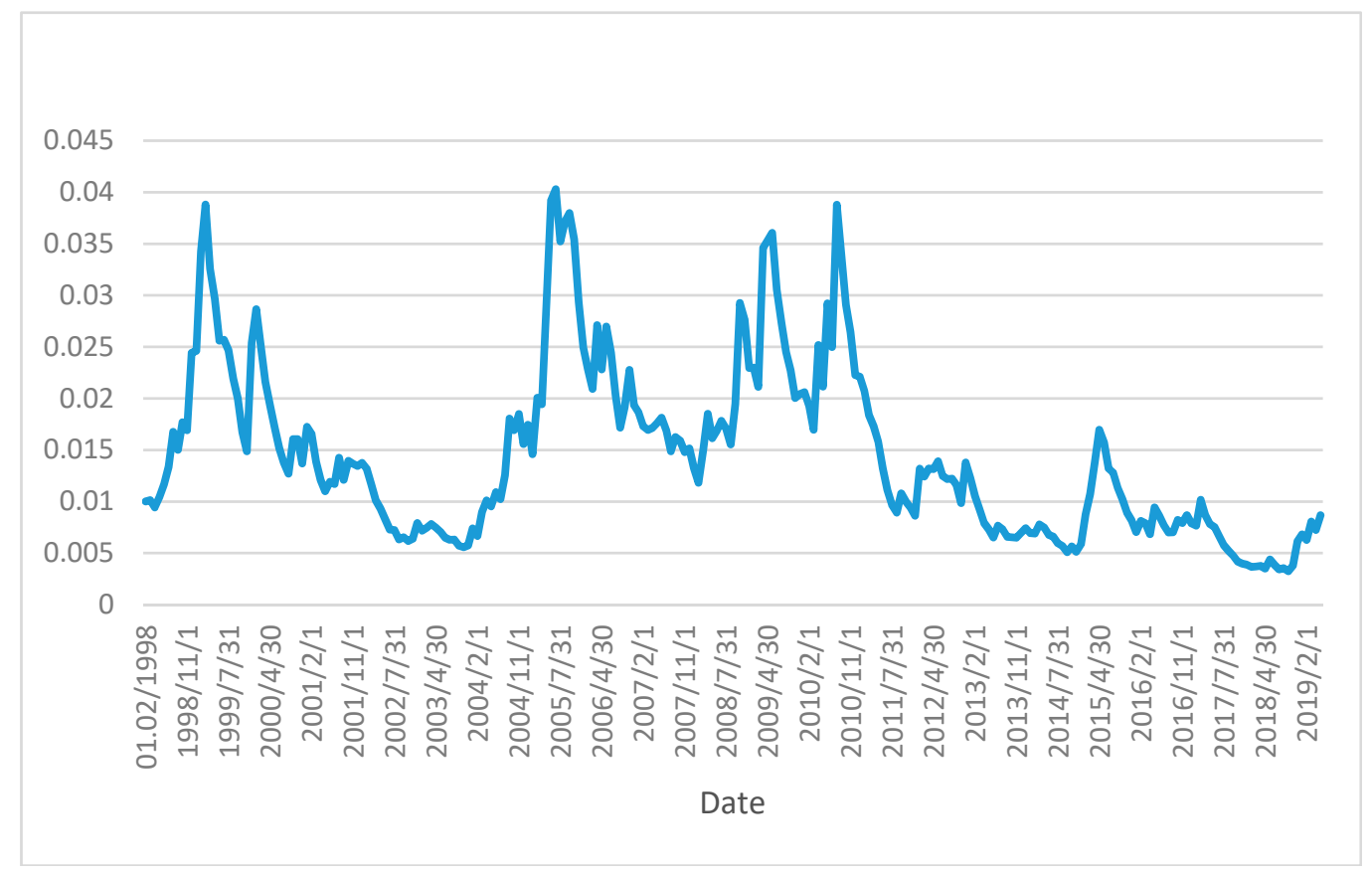

Figure 4. Conditional Volatility for FIH returns.

Adding the oil price returns to the model in Table 3 suggests in all cases that the price of oil has a positive and highly significant effect on the return on FIH. This result reflects the findings from other studies as noted in the literature review. In the case of the intercept long-run dummy variable, this 
now becomes insignificant, whilst the impulse dummy variable is only significant at the $10 \%$ level of significance, suggesting it is the price of oil rather than the discovery of oil that affects the return in the longer term. The significance of oil to FIH returns indicates despite the Falkland Islands business being only a part of FIH, it is this and its links to the oil exploration that are driving its share price. However, when the dummy variable and oil price are added to the conditional volatility equation in the final two columns in Table 3, the dummy variable is only significant when in intercept form, again negatively affecting the volatility although the oil price has no significant effect on the volatility, suggesting the movements in oil prices do not affect the risk of FIH returns, whilst the discovery of oil reduced the stock's risk when the oil was discovered.

Table 3. Estimation of event study model with oil prices and EGARCH model.

\begin{tabular}{|c|c|c|c|c|}
\hline Variable & $2010(3-5)$ & $2010(3-5)$ & 2010-2019 & 2010-2019 \\
\hline \multirow[t]{2}{*}{$\alpha_{3}$} & 0.002 & 0.008 & 0.011 & -0.001 \\
\hline & $(0.263)$ & (0.121) & (1.298) & (0.045) \\
\hline \multirow[t]{2}{*}{$\alpha_{4}$} & 0.310 * & 0.278 * & 0.309 * & $0.383^{* *}$ \\
\hline & (1.851) & (1.64) & (1.887) & $(2.307)$ \\
\hline \multirow[t]{2}{*}{$\alpha_{5}$} & $0.176^{* * * *}$ & $0.169^{*}$ & -0.015 & -0.003 \\
\hline & $(2.76)$ & (1.867) & (1.564) & $(0.196)$ \\
\hline \multirow[t]{2}{*}{$\alpha_{6}$} & $0.297^{* * *}$ & $0.289^{* * *}$ & $0.293^{* * *}$ & $0.320^{* * *}$ \\
\hline & $(4.274)$ & $(4.474)$ & $(4.296)$ & (3.955) \\
\hline \multirow[t]{2}{*}{$\lambda$} & $-0.370^{* * *}$ & $-0.459^{* * *}$ & $-0.321^{* * *}$ & $-7.442^{* * *}$ \\
\hline & (3.419) & $(2.944)$ & (3.334) & (20.101) \\
\hline \multirow[t]{2}{*}{$\beta$} & $0.233^{* * *}$ & $0.241^{* * *}$ & $0.221^{* * *}$ & $-0.179^{* *}$ \\
\hline & $(3.454)$ & $(3.307)$ & $(3.756)$ & $(2.007)$ \\
\hline \multirow[t]{2}{*}{$\gamma$} & -0.039 & -0.045 & -0.073 & 0.042 \\
\hline & $(0.783)$ & $(0.854)$ & (1.408) & $(0.724)$ \\
\hline \multirow[t]{2}{*}{$\phi$} & $0.955^{* * *}$ & $0.938^{* * *}$ & $0.964^{* * *}$ & $-0.861^{* * *}$ \\
\hline & $(43.095)$ & (29.27) & (50.015) & $(12.48)$ \\
\hline \multirow[t]{2}{*}{$v$} & & 0.129 & & $-1.889^{* * * *}$ \\
\hline & & (0.335) & & $(5.823)$ \\
\hline \multirow[t]{2}{*}{$\Delta$ oil } & & 0.516 & & 0.926 \\
\hline & & (1.376) & & (1.429) \\
\hline $\mathrm{Q}(12)$ & 7.882 & 7.605 & 7.805 & 8.925 \\
\hline $\mathrm{Q}^{2}(12)$ & 5.558 & 5.348 & 6.692 & 5.919 \\
\hline
\end{tabular}

Notes: See Equations (2) and (3) for details and Table 2. A*,***** indicates significance at the $10 \%, 5 \%$, and $1 \%$ levels.

\section{Conclusions}

These results suggest that overall the discovery of oil has increased stock returns for FIH above the market, both at the time of the discovery in 2010 and to a lesser extent subsequently. However, the oil price has had an even stronger effect on FIH returns during this era. In addition, there is evidence that the discovery of oil has reduced the volatility and risk of FIH, possibly due to the potential for a more diversified future economy. As FIH is the main trading company in the Falklands, this suggests the potential for the wider economy to benefit in terms of income and stability as a result of the oil. However, the results provide some evidence that the future with regard to oil production and the benefits that should accrue from it will be dependent on the price of oil over forthcoming years.

However, this study is unable to make predictions on the long-term effects of discovering oil, due to the short-term nature of asset markets. To analyse the long-term effects would require information on the island's macroeconomic data, such as economic growth, as well as more specific data on oil reserves. This means that the direct effects on the economy are difficult to ascertain. This could be an area for future research as data becomes available, along with an assessment of the implications of the discovery of oil from the perspective of other disciplines such as political scientists. As with all economies, the Falkland Islands has its own particular political problems. The main difficulty could arise from its relationship with its near neighbour Argentina. Argentina lays claim to the Islands 
and reserves and is threatening to sue companies involved in the exploration process. A further risk involves the potential for prolonged low oil prices, which would make the exploitation of the reserves uneconomical. These factors could be subduing the share price during the time span analysed.

The main implication of the results relates to how oil discoveries affect the stock prices of firms which dominate the economy in a particular country. The main policies that have benefited other countries that have discovered commodities involve a gradual and measured spending of the new wealth whilst increasing saving, such as through a sovereign fund as in Norway. This ensures the new-found wealth will be spread out more evenly across the generations. In addition, as Torvik (2009) indicates, they will need to ensure they have appropriate political and institutional frameworks in place. Currently the Falkland Islands pound is pegged to the UK pound, so the 'Dutch disease' is not likely to occur. However, a pegged exchange rate may inhibit sufficient flexibility in the future monetary position of the Islands to ensure there is enough liquidity to allow the economy to grow reasonably. Monetary changes, such as a looser peg to the UK pound, may be a way round this potential problem.

Funding: This research received no external funding.

Conflicts of Interest: The author declares no conflict of interest.

\section{References}

Binder, John. 1998. The event study methodology since 1969. Review of Quantitative Finance and Accounting 11: 111-37. [CrossRef]

Broadstock, David C., Hong Cao, and Dayong Zhang. 2012. Oil shocks and their impact on energy related stocks in China. Energy Economics 34: 1888-95. [CrossRef]

Castillo, Daniel, and Joseph Falzon. 2018. An analysis of the impact of Wannacry cyberattack on cybersecurity stock returns. Review of Economics and Finance 13: 93-100.

Elyasiani, Elyas, Iqbal Mansur, and Babatunde Odusami. 2011. Oil price shocks and industry returns. Energy Economics 33: 966-74. [CrossRef]

Fernandez-Diaz, Jose M., and Bruce Morley. 2019. Interdependence among agricultural commodity markets, macroeconomic factors, crude oil and commodity index. Research in International Business and Finance 47: 174-94. [CrossRef]

Karl, Terry Lynn. 1997. The Paradox of Plenty: Oil Booms and Petro-States. Berkeley: University of California Press.

Listhaug, Ola. 2005. Oil wealth dissatisfaction and political trust in Norway: A resource curse? West European Politics 28: 834-51. [CrossRef]

Loutia, Amine, Constantin Mellios, and Kostas Andriosopoulos. 2016. Do OPEC announcements influence oil prices. Energy Policy 90: 262-72. [CrossRef]

Mensi, Walid, Shawkat Hammoudeh, and Seong-Min Yoon. 2014. How do OPEC news and structural breaks impact returns and volatility in crude oil markets? Further evidence from a long memory process. Energy Economics 42: 343-54. [CrossRef]

Nelson, Daniel B. 1991. Conditional heteroskedasticity in asset returns: A new approach. Econometrica 59: 347-70. [CrossRef]

Rigobon, Roberto, and Brian Sack. 2004. The impact of monetary policy on asset prices. Journal of Monetary Economics 54: 1553-75. [CrossRef]

Romero-Meza, Rafael, Claudio Bonilla, and Melvin Hinich. 2007. Non-linear event detection in the Chilean stock market. Applied Economics Letters 14: 987-91. [CrossRef]

Rosser, Andrew. 2006. Escaping the Resource curse. New Political Economy 11: 557-70. [CrossRef]

Sachs, Jeffrey D., and Andrew Warner. 1995. Natural Resource Abundance and Economic Growth. NBER Working Paper No. 5398. New York: National Bureau of Economic Research.

Sadorsky, Perry. 1999. Oil price shocks and stock market activity. Energy Economics 21: 449-69. [CrossRef]

Scrimgeour, Dean. 2014. Commodity price responses to monetary policy surprises. American Journal of Agricultural Economics 97: 88-102. [CrossRef]

Shackleton, Lord. 1983. The Falkland Islands and their history. The Geographical Journal 149: 1-4. [CrossRef]

Torvik, Ragnar. 2002. Natural resources, rent seeking and welfare. Journal of Development Economics 67: 455-70. [CrossRef] 
Torvik, Ragnar. 2009. Why do some resource-abundant countries succeed while others do not? Oxford Review of Economic Policy 25: 241-56. [CrossRef]

Zhang, Chuanguo, and Xiaoqing Chen. 2011. The impact of global oil price shocks on Chinese stock returns: Evidence from the ARJI(- $\left.h_{t}\right)$-E-GARCH model. Energy 36: 6627-33. [CrossRef]

(c) (

(C) 2019 by the author. Licensee MDPI, Basel, Switzerland. This article is an open access article distributed under the terms and conditions of the Creative Commons Attribution (CC BY) license (http://creativecommons.org/licenses/by/4.0/). 